\title{
(In)justiça escolar: os paradoxos do processo de democratização e a desigualdade distributiva das oportunidades de acesso à escola e à universidade
}

\begin{abstract}
Resumo
É possível vislumbrarmos uma escola e uma universidade justas no Brasil? Dois planos foram estabelecidos visando responder a esta questão: o primeiro centra-se na produção ideológica de determinados consensos sobre o que se entende por justiça, o segundo refere-se a experiências e sentimentos relativos ao que se considera como injusto. A premissa que orientou a mobilização de matrizes teóricas funda-se na necessidade de promover uma espécie de jogo dos opostos entre justiça e injustiça. John Rawls e Michael Walzer ajudam a refletir sobre as concepções de justiça, Barrington Moore Júnior e François Dubet contribuem no estudo dos sentimentos de injustiça. A partir do diálogo entre esses planos, compusemos figuras da injustiça escolar, tendo como referência representações de professores aposentados da rede estadual de Santa Catarina, abrangendo os paradoxos do processo de democratização da educação e a desigualdade distributiva das oportunidades de acesso à escola e à universidade.
\end{abstract}

Palavras-chave: (In)justiça Escolar. Democratização da Educação. Desigualdade de Oportunidades. Sentimentos de Injustiça.

\section{Para citar este artigo:}

VALLE, Ione Ribeiro. (In)justiça escolar: os paradoxos do processo de democratização e a desigualdade distributiva das oportunidades de acesso à escola e à universidade. Revista Linhas. Florianópolis, v. 19, n. 41, p. 325-349, set./dez. 2018. 


\title{
School (in)justice: the paradoxes of democratization and distributive inequality of opportunities of access to school and university
}

\begin{abstract}
Is it possible for us to envision fair schools and universities in Brazil? Two framework were established to respond to this question: the first focuses on the ideological production of certain consensuses about what is understood by justice. The second refers to experiences and feelings related to what is considered injustice. The premise that guides the mobilization of theoretical matrices is based on the need to promote a type of interplay between the opposites justice and injustice. John Rawls and Michael Walzer help us to reflect on concepts of justice, Barrington Moore Júnior and François Dubet contribute to the study of feelings of injustice. Based on a dialog between these planes we compose figures of school injustice, using as a reference the statement of retired teachers from the state public school network of Santa Catarina, encompassing the paradoxes of the democratization of education and the unequal distribution of opportunities for access to schools and universities.
\end{abstract}

Keywords: School (In)justice. Democratization of Education. Inequality of Opportunities. Sense of Injustice. 
É possível vislumbrarmos uma escola e uma universidade justas no Brasil? É possível vislumbramos a construção de um sistema de ensino (da educação infantil à formação superior) o menos injusto possível, como sugere François Dubet (2008)? É a busca de respostas a estas questões que tem instigado nosso interesse pela discussão sobre a justiça ou, mais propriamente, por aquilo que cada vez mais vem sendo percebido como injustiça. Como se pode ver, estas questões decorrem de uma opção política, qual seja: é preciso continuar desvelando as lógicas que estão por trás da crença num ideal trans-histórico e transcultural de justiça escolar; ideal este operado e legitimado por meio da meritocracia escolar.

Nosso intento não é sucumbir a leituras reprodutivistas que veem o sistema de ensino unicamente como uma máquina infernal, cuja função é selecionar, excluir, fabricar e multiplicar injustiças. Ao formularmos essas questões, fazemos uma aposta nessas instituições porque as vemos como espaços de possibilidades; porque reconhecemos que para a maioria das crianças e jovens brasileiros elas representam a única chance de enfrentar desigualdades e injustiças sociais.

Nossa premissa é que, ao nos referirmos ao termo justiça, somos levados a mobilizar diferentes lentes interpretativas, enquanto que ao tratarmos das injustiças estamos falando necessariamente de experiências, de sentimentos, de pontos de vista. Portanto, refletir sobre a injustiça, seja qual for o sentido que estamos dando a ela, supõe explicitar nosso entendimento sobre a justiça.

Certamente, não é difícil perceber que estamos nos impondo um desafio de grande complexidade, que consistiria em mergulhar numa espécie de baú das memórias filosóficas. Um desafio que nos remeteria à filosofia grega, assim como às múltiplas significações atribuídas à noção de justiça pelos pensadores iluministas. Evidentemente, não será possível colocar essa perspectiva em prática aqui, mas nada nos impede de recorrer, ainda que de forma aligeirada e consequentemente simplificada, à contribuição de algumas dessas reflexões.

Por estarmos nos referindo a um princípio polissêmico, cujo sentido foi sendo redefinido ao longo dos tempos, nossa opção neste momento foi a de dialogar com alguns pensadores contemporâneos que têm não apenas recolocado a discussão, mas, 
sobretudo, oferecido novas base epistemológicas permitindo situar a ideia de justiça, de modo crítico, em diferentes contextos.

Apesar dos termos justiça e injustiça serem objetos de incontáveis juízos, é possível apreender algumas constâncias ao focar experiências e sentimentos por eles suscitados. Parece-nos estar entre essas constâncias o fato de que o que é, ou não, considerado justo ancora-se estritamente em convenções humanas. Em outras palavras, parece pouco pertinente indagar se os danos causados por uma catástrofe natural são injustos. Ora, é recorrente o sentimento de que catástrofes naturais são injustas somente se forem tributárias de ações humanas; podemos lembrar aqui o rompimento da barragem em Mariana em novembro de 2015. O sentimento de injustiça, frente a essa catástrofe, vem do fato de se reconhecer que se tratou de um estrago que poderia e deveria ser evitado; esse estrago deve-se indiscutivelmente às ações humanas, ou à ausência dessas ações.

Mas não seria o caso, por exemplo, das anomalias genéticas que afetam os seres humanos. Elas são justas? Elas são injustas? Não nos é possível emitir um juízo a esse respeito, uma vez que elas se inscrevem naquilo que alguns pensadores, tal como John Rawls, têm caracterizado como "loteria natural" ou como "desigualdades imerecidas", referindo-se aos talentos inatos. Em contrapartida, estamos diante de injustiças quando o que está em questão são as desigualdades resultantes das condições socioeconômicas e culturais de nascimento. Sobre elas pesa, de maneira inquestionável, a chamada "loteria social”. Em sociedades como a nossa, essas desigualdades acabam sendo assumidas como destino - ou como sina -, embora decorram da herança (econômica, social, cultural). Ou, como alertam os sociólogos Bourdieu e Passeron, na obra Os Herdeiros (1964; 2014), o sistema de ensino impõe uma eliminação antecipada que aparece como uma autoeliminação antecipada.

É a partir de algumas dessas constâncias que procuramos estender uma espécie de fio de Ariadne visando combinar reflexões filosóficas sobre a justiça com experiências e sentimentos de injustiça. Nossa intenção foi apreender processos, ainda que complexos, de incorporação e naturalização dessas constâncias. Para orientar a

\footnotetext{
1 Segundo Rawls (2002, § 17, p. 109), “A distribuição natural não é justa nem injusta; nem é injusto que pessoas nasçam em alguma posição particular na sociedade. Esses são simplesmente fatos naturais. $O$ que é justo ou injusto é o modo como as instituições lidam com esses fatos".
} 
elaboração dos nossos argumentos, definimos dois planos: um plano geral relativo à produção ideológica de determinados consensos sobre o que significa justiça, outro plano de menor amplitude vinculado mais diretamente a experiências e sentimentos relativos ao que se percebe como injusto.

Para o primeiro plano, recorremos a algumas ideias situadas na base desses consensos e que compõem uma espécie de legado epistemológico; para o segundo, levantamos noções sobre a democratização da educação, a igualdade de oportunidades e a relação entre educação escolar e justiça, com o objetivo de analisar as representações de uma amostra de professores aposentados da rede estadual de Santa Catarina ${ }^{2}$. Como o período de exercício no magistério desses professores se estendeu de 1940 a 2010, a docência se desenvolveu em momentos diversos da educação brasileira tendo se submetido a diferentes práticas, segundo os regimes políticos, e a um maior ou menor investimento na chamada modernização da educação.

\section{Do legado epistemológico}

O plano geral nos remete, necessariamente, ao legado da Antiguidade Clássica, o qual será abordado aqui unicamente à luz da perspectiva aristotélica, segundo a qual a justiça é uma virtude por excelência, somente podendo ser conquistada quando se age de forma justa. Em outras palavras, a justiça decorre de uma exigência interior, de uma exigência de controle e de equilíbrio próprios, sendo concebida como condição sine qua non de uma vida boa. Esse equilíbrio somente pode ocorrer quando a justiça é, ao mesmo tempo, distributiva (porque centrada na distribuição dos postos, dos fundos e das honras) e corretiva (decorrente das relações contratuais, voluntárias ou involuntárias, fraudulentas ou violentas).

\footnotetext{
${ }^{2}$ A enquete, realizada no quadro do projeto "Educação escolar, justiça social e memória docente: as múltiplas faces das desigualdades escolares em Santa Catarina", aprovado pelo CNPq, abrange 723 professores da rede estadual de ensino do Estado de Santa Catarina e que se encontram na condição de aposentados. Seus dados foram recolhidos por meio de um questionário (aplicado entre março de 2010 e setembro de 2012). Os questionários-fonte utilizados para este estudo não compõem uma amostra estatisticamente representativa do conjunto de professores aposentados, pois não foi possível obter o número exato de docentes dessa rede uma vez que integra a listagem obtida junto aos órgãos oficiais um conjunto diversificado de funcionários que não necessariamente atuaram como professores ou mesmo no magistério. No entanto, conseguimos abranger todos os municípios (dos maiores aos menores) e contemplar ao menos $10 \%$ dos professores que foram contatados em cada município.
} 
Essa abordagem não nos permite esquecer que estamos diante de uma 'virtude compensatória', ou mais propriamente "reparatória", uma vez que ela somente se concretiza quando se dá a cada um o que lhe é devido, e quando todo prejuízo causado a outrem é reparado. Essa perspectiva retém a ideia de que todo privilégio, ou todo tipo de favorecimento, provoca sentimentos de injustiça ${ }^{3}$ induzindo, consequentemente, certos desequilíbrios. Esses desequilíbrios indicam que a justiça distributiva não está desempenhando a contento o seu papel.

À luz desse quadro reflexivo mencionado de forma apressada, podemos considerar que a justiça é vista como uma espécie de 'virtude armada'. Ideia esta que pode ser observada apreciando-se os afrescos de Ambrogio de Lorenzetti, pintados no Palácio público de Siena (Itália) entre 1317 e $1348^{4}$. Esses afrescos podem ser lidos como alegorias do bom e do mau governo. É principalmente a representação da justiça como sapiência que se destaca nessas obras, ou seja, trata-se da representação de uma ideia de justiça que coloca em equilíbrio duas dimensões, a distributiva e a corretiva. Essas dimensões são apresentadas através de dois pratos. É o equilíbrio entre eles que distingue um governo bom de um mau governo.

Continuando no plano das ideias e, ao mesmo tempo, atravessando séculos de reflexão filosófica, lembramos que "é na Antiguidade Clássica que os iluministas vão buscar inspiração", que é lá que eles vão encontrar os elementos-pilares para "construir uma sociedade onde se faria cada vez menos apelo à forca física dos homens e cada vez mais à sua força intelectual” (VALLE, 2010, p. 26). Num contexto marcado pela lógica racional, ao invés de ser lida tão somente como virtude, a justiça passa a ser interpretada

\footnotetext{
${ }^{3}$ Segundo Rawls (2002, p. 11), "O sentido mais específico que Aristóteles atribui à justiça, e do qual derivam as formulações mais conhecidas da justiça, é o de evitar a pleonexia, isto é, evitar que se tire alguma vantagem em benefício próprio tomando o que pertence a outrem, sua propriedade, sua recompensa, seu cargo, e coisas semelhantes, ou recusando a alguém o que lhe é devido, o cumprimento de uma promessa, o pagamento de uma dívida, a demonstração do respeito devido, e assim por diante".

4 O primeiro representa esta ideia de "virtude armada", e pode ser visto na página: <https://www.google.com.br/search?q=frescos+de+ambrogio+lorenzetti\&rlz=1C1GGGE_ptBRBR427BR428\&espv=2\&source=Inms\&tbm=isch\&sa=X\&ved=0ahUKEwizoaaPy8_TAhUFTZAKHeM7CHsQ_ AUIBigB\&biw=1366\&bih=643\#imgrc=uVRWWIlhM7lU1M:>; o segundo diz respeito mais diretamente à noção de equilíbrio, representada por meio dos dois pratos: $<$ https://www.google.com.br/search?q=fresque+d\%27ambrogio+lorenzetti+le+bon+gouvernement\&rlz=1C1 GGGE_pt-

BRBR427BR428\&espv=2\&tbm=isch\&tbo=u\&source=univ\&sa=X\&ved=0ahUKEwi8uZbg07DTAhUlgmMKHQR rBOEQSAQIMQ\&biw=1366\&bih=643\#imgrc=kF7N2vFRZwnK3M:>.
} 
como princípio, remetendo a direitos e deveres. Daí a importância atribuída à noção de justiça por Jean-Jacques Rousseau (1712-1778), particularmente na obra Emílio ou da educação (1762). Segundo ele, a justiça é uma das virtudes que mais concorre para o bem dos homens. Por essa razão, ela deve ser alcançada por intermédio da educação, o que aponta para a necessidade de se estabelecer uma aliança entre educação e justiça.

Mas essa aliança não é idealizada exclusivamente por este filósofo; ela está presente no espírito das luzes. Pode-se lembrar aqui do Marquês de Condorcet (17431794) que, por meio das suas reflexões sobre a instrução pública (1791), insere a educação no quadro dos direitos do cidadão. Desde então, a educação passa "a compor a agenda dos projetos republicanos e a integrar algumas iniciativas liberais. Se outrora ela [a educação escolar] era vista como uma questão familiar e de interesse individual, ficando ao abrigo de todo debate sobre a justiça, ao ser considerada como um direito se torna de interesse de todos" (Valle, 2014c, p. 17-18). Desse modo, tanto a ideia de justiça como virtude ou de justiça como princípio, quanto a aliança entre educação e justiça, podem ser mencionadas como constâncias que atravessam os tempos, produzindo determinados consensos que são facilmente perceptíveis no imaginário social.

Esses consensos adquirem grande importância quando se quer refletir sobre o que poderia definir ou caracterizar uma escola e uma universidade justas. Diferentes matrizes teóricas têm instigado essa perspectiva analítica. Priorizamos, neste momento, as abordagens de quatro pensadores, pertencentes a diferentes campos epistemológicos 5 . A premissa que orienta essa escolha funda-se na necessidade de fazer uma espécie de jogo dos opostos - ou jogo de espelhos - entre justiça e injustiça. Enquanto John Rawls (2002) e Michael Walzer (2003) se dedicam à redefinição da noção de justiça, Barrington Moore Júnior (2005) e François Dubet (2014) focam, predominantemente, nos sentimentos de injustiça.

Da obra de John Rawls ${ }^{6}$, intitulada Uma teoria da justiça, publicada originalmente em 1971, buscamos a noção de “justiça como equidade”, elaborada a partir da reinterpretação das teorias do contrato social. Para Rawls (2002, p. 6), "As instituições são justas quando não se fazem distinções arbitrárias entre as pessoas na atribuição de

\footnotetext{
${ }^{5}$ Sobre esta discussão teórica, ver, sobretudo, Valle (2013, p. 659-671).

${ }^{6}$ Sobre os princípios de justiça e justiça escolar, ver, também, Rohling e Valle (2016, p. 386-409).
} 
direitos e deveres básicos e quando as regras determinam um equilíbrio adequado entre reivindicações concorrentes das vantagens da vida social”. Segundo Valle (2013, p. 664), é "a influência de sua teoria na definição das políticas educacionais atuais [...], nas quais as medidas compensatórias ou reparadoras ocupam um lugar de destaque”, que permite situá-lo no movimento que vislumbra uma escola e uma universidade justas.

Da obra de Michael Walzer, publicada originalmente em 1983, intitulada Esferas da justiça: uma defesa do pluralismo e da igualdade, extraímos a ideia de "sociedade complexamente igualitária", introduzida a partir da moral de fundo aristotélico, alicerçada, portanto, em virtudes e não em princípios universais. Sua teoria não preconiza a eliminação de todas as desigualdades, pois, segundo ele, o problema não são as desigualdades em si, mas, as relações de dominação: “O que a justiça requer é que nenhum bem social possa servir de meio de dominação" (WALZER, 2003, p. 12). Segundo Valle (2013, p. 665), “a educação é, para Walzer, uma das esferas da justiça. Por essa razão, sua perspectiva teórica assume uma grande importância nas (re)definições das políticas educacionais atuais e, evidentemente, nas discussões a respeito do que seria uma escola justa".

Da obra de Barrington Moore Júnior, publicada inicialmente em 1978, intitulada Injustiça: as bases sociais da obediência e da revolta, surge o interesse pelas tendências históricas que fundam as noções de (in)justiça, assim como pelos fatores que provocam variações de apreensão e de ação em certos grupos sociais. Para Moore Júnior (1987, p. 687), "A forma de crítica realmente subversiva tem início quando as pessoas perguntam se uma função social específica necessita realmente ser desempenhada, se reis, padres, capitalistas e mesmo burocratas revolucionários não seriam desnecessários à sociedade humana". Segundo Valle (2013, p. 665), o que chama a atenção deste autor é “o sentimento que emerge do conflito inerente às demandas de igualdade e às justificações dos dominantes para as desigualdades. Esse conflito desvela lógicas da desigualdade social que podem tornar-se fonte da ira moral e da recusa do sofrimento e da opressão, fomentando assim o senso de injustiça social”.

Da obra de François Dubet (1946-), intitulada Injustiças: a experiência das desigualdades no trabalho, publicada originalmente em 2006, retivemos o que ele caracteriza como poliarquia dos princípios de justiça, ao tratar de três deles: a igualdade, 
o mérito e a autonomia, entendendo que estes são apreendidos de maneira muito diversa segundo os contextos e os interesses. Para Dubet (2014, p. 22), "As críticas dirigidas às condições e relações de trabalho se impõem como uma força particular porque o trabalho cristaliza um conjunto de mecanismos e de relações sociais particularmente propícias à manifestação do sentimento de injustiça". Segundo Valle (2013, p. 666-667), a contribuição de Dubet permite colocar em xeque dois princípios pilares da escola republicana: a igualdade de oportunidades e o mérito escolar. "O primeiro é considerado como um dos princípios mais evidentes e mais complexos da justiça; o segundo é incontornável na imagem de um mundo justo, no qual cada um seria recompensado em função de seu mérito, de seus esforços e, consequentemente, dos resultados alcançados".

É importante considerar que essas reflexões, cada uma a sua maneira, têm como alvo os diferentes tons das desigualdades nas sociedades contemporâneas. Na verdade, no campo educacional, dispomos há bem mais de meio século de uma produção teórica abundante, que comprova os impactos dos fatores socioeconômicos e culturais sobre o processo de escolarização, graças à análise das trajetórias dos alunos, das práticas e veredictos dos professores, da formação para o magistério, da qualificação para o trabalho. Referimo-nos, por exemplo, a trabalhos de sociólogos franceses, como os de Bourdieu e Passeron (1964; 1970) sobre os paradoxos da democratização da educação, sobre a violência simbólica, sobre o papel da educação escolar na reprodução das elites. Mas também lembramos as contribuições mais recentes de sociólogos, também franceses, como Dubet (2008; 2014); Charlot (1997); Lahire (1998), dentre tantos outros. Evidentemente, as referências utilizadas pelos pesquisadores brasileiros não são apenas as da sociologia francesa ${ }^{7}$, mas são essas que vamos priorizar neste momento.

Esse leque de teorias tem possibilitado aos pesquisadores em educação desnudar a complexa teia de mecanismos promotores da diversificação, da multiplicação e da reprodução das desigualdades escolares, postos em prática pelos sistemas de ensino. Além disso, essas teorias têm dado suporte argumentativo a movimentos voltados à democratização da educação e às mudanças nas nossas políticas educacionais.

\footnotetext{
${ }^{7}$ Ver, por exemplo, Valle (2014b).
} 
Apesar disso, continuamos a conviver, e a nos surpreender a cada novo estudo concluído, com um sistema de ensino que se expandiu consideravelmente, às vezes de forma desordenada e mercadológica, como no caso da formação universitária, com um sistema de ensino submetido a uma importante "demografização" 8 escolar, sem de fato ter se democratizado e, muito menos, avançado na direção de uma escola e de uma universidade justas. Sendo a escola vista como uma instância de promoção da justiça, presume-se que o acesso a ela deva estar assegurado a todos, principalmente porque, nos dispositivos legais voltados à educação brasileira, ao menos desde os anos 1930, ela é apresentada, ainda que de forma controversa, como um direito, estando inscrita na ordem das obrigações da família e do Estado.

A partir dessas múltiplas inspirações teóricas, procuramos compor, para a reflexão deste momento, duas figuras da injustiça escolar, tendo em mente consensos que foram se cristalizando ao longo dos tempos. Estas figuras abrangem formas de elocução suscitadas por experiências, sentimentos, pontos de vista. A primeira coloca em evidência os paradoxos do processo de democratização da educação; a segunda diz respeito à desigualdade distributiva das oportunidades de acesso à escola e à universidade. Para delinear os contornos destas figuras, tomamos como parâmetro as representações de professores catarinenses que se encontram na condição de aposentados, como mencionado anteriormente. A premissa que orientou a composição desses retratos pauta-se no fato de que "ao levantar as significações da palavra justiça, percebemos que diferentes perspectivas etimológicas e epistemológicas se mesclam e que há uma relação muito íntima entre os usos de senso comum e os usos fundados nessas perspectivas" (VALLE, 2010 p. 23).

Evidentemente, isso não nos surpreendeu, pois essas teorias (filosóficas ou sociológicas) estão cada vez mais ao alcance dos professores, seja por meio da formação inicial, seja nos cursos de formação continuada, o que os leva a mobilizar com relativa facilidade ideias que vão do pensamento clássico ao pensamento contemporâneo. Na

\footnotetext{
${ }^{8}$ Segundo Langouët (2002), o termo "demographisation" foi empregado primeiramente pelo historiador francês Antoine Prost na obra "L'enseignement s'est-il démocratisé?" (publicada em 1986). Ao constatar que o crescimento das oportunidades de acesso ao sistema de ensino nem sempre vem acompanhado de uma ampliação das chances escolares, o autor emprega o termo para se referir especificamente aos movimentos de expansão quantitativa, os quais não necessariamente provocam uma democratização da educação.
} 
verdade, os professores têm se colocado cada vez mais em contato com abordagens teóricas, apropriando-se, ainda que de forma fragmentada, descontextualizada ou até mesmo contraditória, de uma espécie de retórica epistemológica pouco embasada epistemologicamente.

\section{Figura 1: Os paradoxos do processo de democratização da educação}

Como paradoxos do processo de democratização da educação, consideramos a "dupla verdade" da instituição, que consiste em colocar a lógica interna de funcionamento a serviço da função externa de conservação e reprodução social. A partir deste pressuposto, solicitamos aos professores que fizessem uma avaliação das políticas educacionais implementadas pelo Estado brasileiro. Percebemos, desde o início do levantamento dos dados, que o chamado "processo de democratização da educação", desencadeado em Santa Catarina nos anos de 1980, não havia sido apreendido pelos professores de modo similar, ao contrário, o mesmo foi marcado por mal-entendidos.

Como mostram vários estudos ${ }^{9}$, o processo de democratização da educação apresentou um grande vigor, de modo que a maioria dos professores (quase $90 \%$ deles se aposentou entre 1980 e 2010) esteve, mais ou menos, envolvida em assembleias ou conferências promovidas, além de ter participado direta ou indiretamente da aplicação das medidas dele decorrentes. Nossa premissa é que, mais do que visar à melhoria das condições de escolarização das crianças e jovens catarinenses, esse processo favoreceu leituras paradoxais associadas aos interesses em disputa, envolvendo todos os segmentos dos sistemas de ensino.

De imediato foi possível perceber que a temática democratização da educação não sensibiliza fortemente os professores: quase $40 \%$ deles optaram por não emitir suas opiniões ( $50 \%$ dos professores de $1^{\mathrm{a}}$ a $4^{\mathrm{a}}$ série e $28 \%$ dos que atuaram nos níveis fundamental e médio). Observou-se também que a maior ou menor disposição para opinar sobre esse assunto esteve relacionada principalmente ao nível de formação ${ }^{10}$.

\footnotetext{
${ }^{9}$ Ver, por exemplo, Valle (1996).

${ }^{10}$ Segundo Valle (2014a, p. 353), a amostra utilizada para este estudo assim se distribuiu, segundo os níveis de formação: "Os professores que atuaram apenas no ensino de $1^{\mathrm{a}}$ a $4^{\mathrm{a}}$ série são os que apresentam os níveis mais baixos de formação: $26 \%$ têm um diploma de ensino superior, tendo cursado sobretudo
} 
Evidencia-se, assim, que as representações dos professores acerca da democratização da educação têm uma ligação estreita com sua formação para o exercício do magistério. Ou seja, o "efeito formação" não pode ser negligenciado, pois os professores que atuaram nas séries iniciais, portadores do título universitário, assim como seus colegas atuantes nos níveis fundamental e médio, demonstraram maior disponibilidade para explicitar seus pontos de vista. No que concerne ao teor das suas apreciações, diferentemente do que esperávamos, não foram observadas grandes diferenças, segundo o nível de atuação, o que permite concluir que a formação superior ${ }^{11}$ difundiu, com maior ou menor intensidade, uma perspectiva relativamente análoga sobre as políticas educacionais, em geral, e sobre as políticas de democratização da educação, em particular.

A partir dos percentuais de respostas, mas principalmente das justificativas que acompanharam suas respostas, foi possível observar que os professores mobilizam parâmetros teóricos, assim como convicções axiológicas, para fundamentar suas definições e sustentar seus argumentos. Esse procedimento permitiu contemplar diferentes aspectos da democratização da educação, em conformidade com as posições que os professores assumiram ao longo do processo: de agente participativo e propositivo ou de espectador crítico. A análise desses argumentos apontou para o fato de que as políticas educacionais foram apreendidas de forma paradoxal, como lembra Bourdieu (1998, p. 145-183) ao pôr em perspectiva a democratização da educação na França. Ou seja, ao invés de se voltar à consolidação da aliança entre educação e justiça social, o processo de democratização acabou respondendo a um determinado projeto político do Estado, que não priorizou a oferta de escola pública de qualidade para todos.

\footnotetext{
pedagogia (destes $54 \%$ têm também um diploma de pós-graduação); 61\% são diplomados na escola normal; $7 \%$ cursaram o ginásio normal; $4 \%$ fizeram apenas o ensino primário. O nível superior sobe para $71 \%$ entre os professores que atuaram de $1^{\mathrm{a}}$ a $8^{\mathrm{a}}$ série (44\% deles fizeram pós-graduação); $27 \%$ cursaram o ensino normal e $1 \%$ tem apenas o ginásio normal. 0 nível de escolarização cresce ainda mais quando se trata dos professores que atuaram de $5^{\mathrm{a}}$ a $8^{\mathrm{a}}$ série e no ensino médio: $88 \%$ obtiveram um diploma de ensino superior (59\% deles têm também um diploma de pós-graduação); 10\% cursaram apenas o ensino normal."

${ }^{11}$ É importante assinalar que, além da formação superior, mais da metade dos professores frequentou cursos de pós-graduação (VALLE, 2014a, p. 353) e que houve um grande investimento em cursos de formação continuada promovidos pela Secretaria de Estado, desde os anos 1980; muitos desses cursos resultaram de parcerias com diferentes universidades (VALLE, 2003).
} 


\section{Um processo político-administrativo sob o jugo do Estado}

Um primeiro aspecto a ser destacado nos argumentos dos professores diz respeito ao processo lento, gradual e sujeito às pressões políticas, que caracterizou a democratização da educação em Santa Catarina. Embora todo o processo tenha sido considerado como uma necessidade, tanto para o ensino, quanto para a sociedade, a alusão às medidas implementadas se restringe às iniciativas encabeçadas pelo Estado, nos âmbitos nacional ou estadual. Em outras palavras, todo o movimento foi interpretado como um procedimento meramente político-administrativo, ora licencioso demais ora excessivamente autoritário: "teve início com a elaboração da Proposta Curricular”; "não há democratização pois é necessário seguir os livros que vêm do MEC"; "encontra-se dificuldade no processo devido ao próprio sistema que determina"; "a maioria das diretrizes vêm formadas e ditadas pela Secretaria da Educação. Os professores têm liberdade de trabalho em sala de aula, mas são isolados do contexto da educação"; “quem faz as leis e regras, muitas vezes nem entrou em uma sala de aula". Ou seja, constituiu-se fundamentalmente num processo alheio aos objetivos (pedagógicos) e aos interesses (profissionais) dos professores, estando unicamente sob o jugo do Estado.

\section{Um processo marcado por mal-entendidos}

Um segundo aspecto observado refere-se ao fato de que se trata de um processo pontual, ditado pelas finalidades e metas de cada governo. Consequentemente, embora seja lembrado pela forte mobilização (de administradores, professores, pais, alunos) em favor da educação, o processo suscitou pouco ou nenhum apelo à participação nos espaços decisórios e nas deliberações pedagógicas. Portanto, não houve consenso entre os professores quanto à avaliação do processo de democratização: a maioria o considerou negativo, frágil, inconcluso ou parcial ("não funcionou”; “ficou só no papel”; “não existe”; “não é grande coisa”; “caminha muito devagar”; “que democratização?”; "só existe quando se é livre para ensinar, pensar e agir"; “a ideia é interessante, mas a forma de aplicação deve ser revista"). Já os professores que viram o processo como positivo, apresentaram justificativas bastante genéricas: “vem ao encontro dos anseios da sociedade, é necessária”; “toda mudança vem para trazer benefícios”; “os professores têm tudo à disposição"; "participei e acredito que valeu a pena, pois, até hoje está 
cumprindo sua missão"; "visa descentralizar, municipalizar, expandir o ensino em Santa Catarina”; “com a democratização, nós professores, podemos reivindicar direitos"; "temos mais voz e vez".

\section{Uma democratização "mascarada"}

Um terceiro aspecto a ser mencionado tem relação com o sentimento de que existe uma democratização apenas aparente, que "fica no discurso", atrelada às decisões “de cima", vindas da "gerência”, ancorada num envolvimento mínimo da escola e dos seus profissionais: "para mim a democratização da educação é quando todos têm a oportunidade de participar do PPP ${ }^{12}$. Segundo boa parte dos professores há uma confusão entre democratização e protecionismo, uma vez que os cargos administrativos se transformaram em "cabides de emprego", passando a depender unicamente "de lado ou [de] partido político". É o tom de denúncia que predomina aqui, principalmente quando a questão diz respeito à escolha de diretores. Estão em disputa, portanto, duas modalidades de participação: a da democracia representativa, legitimada pelo voto, e a da meritocracia, legitimada por concurso (a escolha deveria "ficar a cargo da comunidade ou [ser por] concurso público"; deveria ocorrer “por eleição, não por indicação”). Para esses professores, a democratização “nunca existiu, [pois] a política partidária não deixa"; "enquanto o governo insistir em nomear diretores para as escolas, não há democracia”; “poderia ser melhor, não fosse a política”. Trata-se, assim, de "uma democratização 'mascarada', uma vez que mesmo o diretor é escolhido pelos políticos, que o [até mesmo o] livro didático é o governo que escolhe". Ou seja, a escola "não [se] democratizou, [ao contrário, tornou-se] mais ditatorial", porque o processo "foi mal interpretado", porque "estamos ainda muito distantes de uma verdadeira democratização [pois] precisa empenho de professores, alunos, diretores para se conseguir mais autonomia na gestão escolar no que se refere ao pedagógico".

\footnotetext{
${ }^{12}$ Projeto Político Pedagógico.
} 


\section{Autonomia como princípio de justiça descurado}

Essa subordinação da escola ao poder estatal remete a um quarto aspecto: a falta ou perda de autonomia. Grande parte dos professores entende que "diretores [nomeados politicamente] não têm autonomia" e que, consequentemente, ainda se está “longe de ter a escola que sonhamos pois o Estado não oferece autonomia para que as [mesmas] possam investir mais na eficiência e na qualidade de suas ações educacionais". Eles julgam ainda que "a descentralização do poder gestor da escola passa pelo incentivo à participação da comunidade escolar, [o qual] geralmente é incipiente, refletindo a pouca experiência democrática dentro e fora da escola e um cotidiano escolar fragmentado entre quem manda e quem executa". Mas essa falta de autonomia também se evidencia na relação pedagógica, marcada pela perda de autoridade e de respeito: "ela só veio para tirar a autoridade do professor"; "os alunos não obedecem mais os professores"; há "um desmoronamento de valores"; "havia mais rigidez, respeito e o professor era mais valorizado e amado". Segundo esses professores, a democratização “virou desobrigação", tendo provocado um “excesso de pessimismo", decorrente sobretudo da desvalorização (salarial) do magistério e da falta de motivação: "os professores não estão sendo reconhecidos pelo seu trabalho"; "falta a valorização profissional do professor que vive desmotivado, além do salário baixo e dos recursos didático-pedagógicos da escola serem fracos".

Apesar de grande parte dos professores concordar que existe "hoje uma maior liberdade de expressão para o aluno", assim como para o professor, a democratização somente pode existir "quando o professor tiver autonomia para trabalhar e fazer suas atividades de acordo com as diferenças culturais, sociais e religiosas", quando "os alunos se dedicarem mais aos estudos e [às] orientações dos seus professores", quando houver "mais comprometimento com a educação", enfim, quando a educação contar com professores bem preparados, com alunos mais interessados e pais mais participativos. Eles alertam também para os efeitos perversos que a democratização pode provocar: "a liberdade dos alunos na escola tem prejudicado muito o aprendizado"; "a democratização sem limites gera o contrário do que se espera de um país: gera a anarquia". 


\section{A “meta qualitativa” envolvendo aluno e professor ficou prejudicada}

Um último aspecto, elaborado a partir da leitura dos professores sobre o processo de democratização, aparece na vinculação deste com os procedimentos avaliativos e as condições infraestruturais. Em outras palavras, a democratização embaralha-se com o "avanço progressivo", com o fato deste ter se transformado em "promoção automática", limitando-se ao "cumprimento de normas" ("Não concordo com alguns métodos de avaliação do aluno 'tem que aprovar de qualquer jeito"”; "na maneira de avaliar ocorrem muitas desigualdades"). O resultado disso é que o processo de democratização submeteu a educação a "altos e baixos", a "avanços e recuos", tendo causado a queda do nível de ensino ao "promover quem não aprendeu", ao "aprovar quem sequer sabe ler". Eles sugerem frente a essas constatações que "a avaliação deva ser rediscutida culminando com a compreensão do que afinal é o sentido e significado da disciplina". Mas a democratização também encontra seus obstáculos, embora com menor ênfase, na carência de "materiais" humanos e escolares e na decadência dos espaços: "ainda faltam muitas coisas em todos os sentidos, escolas equipadas, professores capacitados e com salários bons"; "melhorou, mas poderia ser melhor com a era da tecnologia"; "só não melhora a educação por falta de material humano que se empenhe ou busque melhorias"; "existem escolas que deveriam ser melhoradas"; “o governo deveria pagar melhor salário"; e possibilitar "habilitação a diversos professores".

Como demonstrou a análise apresentada acima, as relações no interior do sistema de ensino são assimétricas: o métier de professor entra o tempo todo em choque com o métier de aluno; o métier de professor se defronta recorrentemente com o métier de diretor; o exercício do métier de professor geralmente não condiz com as prioridades das instâncias administrativas e pedagógicas do sistema de ensino. Nessa perspectiva, as políticas de democratização, ao invés de promoverem uma educação de qualidade para todos, acabam obnubilando o impacto das desigualdades sociais sobre as desigualdades escolares. Em outras palavras, princípios essenciais à construção de uma escola e universidade justas deixam de ser tratados como prioridade, ficando expostos a interesses do jogo político-partidário; um jogo que muitas vezes lhes parece cifrado. São dimensões desse jogo que vamos mobilizar para esboçar a segunda figura das injustiças escolares no Brasil: a desigualdade distributiva das oportunidades. 


\section{Figura 2: Desigualdade distributiva das oportunidades de acesso à escola e à}

universidade

Visando apreender a relação bastante imprecisa entre avanços e limites das políticas educacionais, solicitamos aos professores que atribuíssem uma nota (numa escala de zero a 10) à igualdade de oportunidades escolares em Santa Catarina. Presumimos que o critério empregado para avaliar o desempenho dos alunos e emitir veredictos escolares poderia ser adotado na apreciação dessa faceta da democratização. Fomos surpreendidos com os índices de respostas: aproximadamente $75 \%$ (sendo $63 \%$ dos professores de $1^{\mathrm{a}}$ a $4^{\mathrm{a}}$ série e $84 \%$ dos que atuaram nos ensinos fundamental e médio); índices bem mais elevados que os encontrados anteriormente. $O$ "efeito formação" se evidenciou mais uma vez, mas não com a mesma intensidade observada até então. Em outras palavras, os professores se mostraram bastante atentos à expansão das oportunidades, não apenas ao atribuírem uma nota às políticas destinadas a esse fim, mas sobretudo ao formularem seus argumentos para justificar as respectivas notas.

Gráfico 1 - Nota atribuída pelos professores à igualdade de oportunidades em Santa Catarina

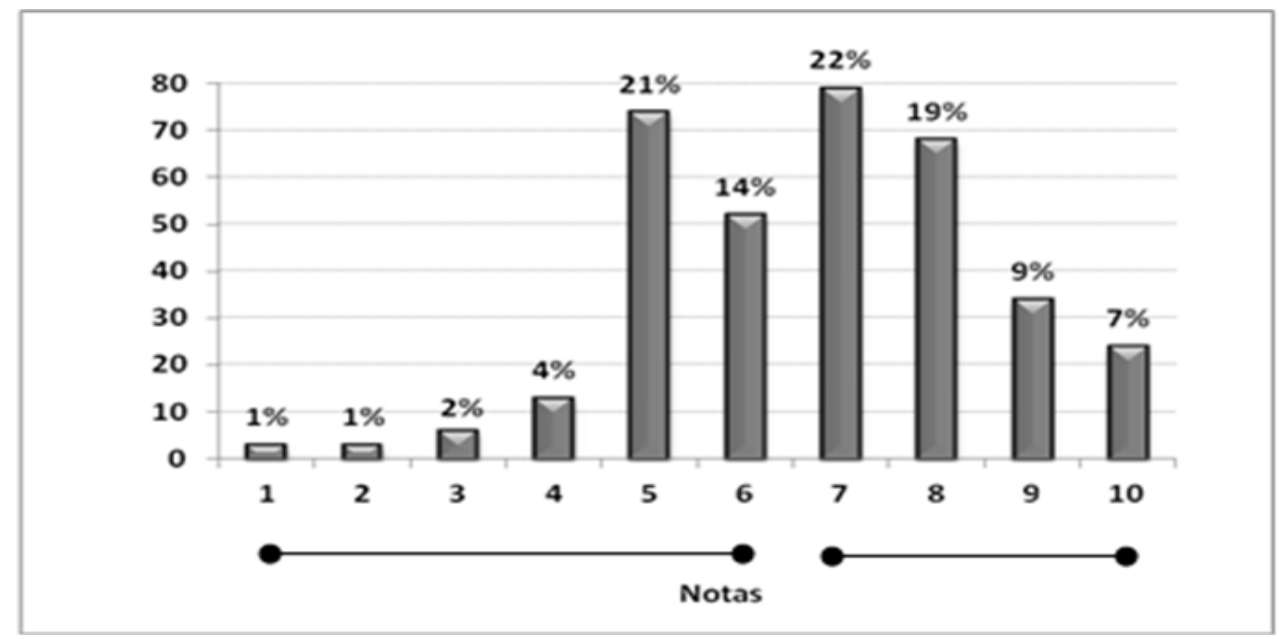

Fonte: Acervo do Projeto "Educação escolar, justiça social e memória docente: as múltiplas faces das desigualdades escolares em Santa Catarina” (2015-2018).

Certamente, pode parecer de pouco interesse o simples fato de atribuir uma nota, apesar disso, observamos que ela acaba orientando a justificativa, podendo constituir-se numa base interessante de informação, além de fornecer um ponto de partida para a 
leitura dos argumentos apresentados. Como se pode observar no gráfico 1, os professores reconhecem os avanços em termos de ampliação das oportunidades de escolarização: $57 \%$ deles emite notas entre sete e dez. Se considerarmos que a nota cinco aparece como linha divisória entre aprovação e reprovação, esse índice sobe para 82\%.

Ao analisar os argumentos elaborados para justificar as notas dadas à igualdade de oportunidades, percebemos que, também aqui, entram em cena, diferentes aspectos, alguns positivos, outros negativos; seus argumentos oscilando muitas vezes de um polo ao outro (da igualdade à desigualdade, da justiça à injustiça). Assim, a referência à igualdade de oportunidades remete, para início de conversa, a uma das dimensões, provavelmente a que mais se sobressai, da relação entre educação e justiça social: o direito constitucional à educação. É o fato de se sentir lesado, ou de perceber que muitos alunos foram prejudicados porque o Estado não ofereceu as condições necessárias ao cumprimento desse direito que gera sentimentos de injustiça. É consenso que, sendo "a educação obrigatória por lei", “todos os alunos têm o direito de frequentar as aulas e aprender".

\section{A ação do governo em favor da ampliação das oportunidades}

Iniciemos com o reconhecimento, por uma parte significativa dos professores, de que houve esforço do governo para garantir o acesso à escola, inclusive por meio da instituição de uma "política de inclusão", sobretudo no que concerne ao ensino fundamental. Ora, está subjacente a esse reconhecimento a ideia de que o dever do Estado em matéria de educação não foi historicamente levado a sério, o que os instiga a reagir positivamente às medidas adotadas para esse fim. Para um número significativo deles "há mais oportunidades em todos os sentidos", "é muito mais fácil estudar do que [outrora], porque tem ônibus pelo interior todo, porque os alunos ganham uniformes". Eles assinalam que "na rede pública há vagas, basta buscá-las", que "há escola para todos", que "todos têm acesso à escola com formação no ensino médio ou técnico", que para os que trabalham "tem [aulas] nos três períodos, que existe "curso superior ou técnico a distância, ao alcance de todos". Eles declaram ainda que o "governo investe muito mais para manter o aluno na escola", colocando "ao alcance do povo boas escolas, bons e valorizados professores", e que "houve inclusão dos portadores de necessidades 
especiais", de modo que "todos têm acesso ao que almejam". Eles também reconhecem que a implantação dessas políticas exigiu "um trabalho grande das escolas para que houvesse compreensão por parte de toda a sociedade" e que "os educadores estão entendendo que todos devem aprender", que "todos são iguais".

\section{O estado crônico das desigualdades escolares}

Um segundo aspecto, sendo predominante aqui o tom crítico, diz respeito à constação de que as desigualdades de acesso à escola e à universidade se tornaram crônicas, acentuando-se e diversificando-se cada vez mais. Ao admitir que tenha havido avanços nas políticas de ampliação das oportunidades escolares, muitos professores se tornam ainda mais sensíveis às desigualdades que elas engendram, demonstrando estar, em grande medida, familiarizados com as teorias sociológicas que desnudaram, desde meados do século passado, a face reprodutora dos sistemas de ensino. É esse estado crônico, essa experiência com as taxas de "mortalidade escolar" (BOURDIEU; PASSERON, 2014, p. 23), que os leva a olhar com profundo pessimismo as chances de prolongamento da escolarização das camadas sociais mais desfavorecidas.

Na opinião desses professores, nem mesmo "a meta quantitativa" foi alcançada: “as oportunidades são desiguais"; "a oportunidade ainda não é para todos”; "os mais pobres ainda têm menos oportunidades"; "o pobre é esquecido"; "as oportunidades não são suficientes"; "há muitas crianças e jovens fora da escola"; "ainda há muitos analfabetos"; "muitos pais têm que dormir na fila para conseguir uma vaga”; "tem muita criança fora da escola por não possuir meios de transporte e até mesmo uniforme, [ou] roupas adequadas ao frio"; "nem todos têm acesso à universidade”. Enfim, eles também entendem que "falta incentivar os bem pobres a estudar e trabalhar para saírem da miséria" e que "as pessoas com mais poder aquisitivo acabam conseguindo mais bolsas de estudo e entram com mais facilidade na universidade”. As diferenças regionais aparecem como mais um indicador de desigualdades e de injustiça: “depende de região para região"; "no interior há mais oportunidade de vagas, nas escolas, mas nas cidades grandes, nem sempre há escolas e vagas para todos". Mas eles também sabem que "no interior os alunos não têm disponíveis todos os recursos que existem nos centros maiores" e que "ainda se tem dificuldades para chegar a uma faculdade". 


\section{O impacto das diferenças socioeconômicas no acesso e na escolha das famílias}

Um terceiro aspecto a ser destacado, também vinculado ao estado crônico das desigualdades de acesso, refere-se às diferenças socioeconômicas, com impactos em todos os níveis de ensino: "há uma enorme distância relativa ao poder aquisitivo"; "existe muita desigualdade entre pobres e ricos"; "algumas classes sociais são mais privilegiadas"; "quem realmente precisa nem sempre é quem ganha a oportunidade"; “pobre não pode pagar cursinho pré-vestibular"; “quem estuda nas universidades públicas são os filhos dos ricos, porque o pobre precisa trabalhar para estudar"; "os mais pobres precisam ajudar seus pais na lavoura e não têm a oportunidade de estudar". Essas diferenças têm consequências sobre as escolhas das famílias, pois "não se pode comparar pública e privada, portanto não há igualdade"; "quem tem condições opta por escola particular"; "quem estuda em escolas particulares tem mais oportunidades"; "os que estudam em escolas particulares saem mais preparados para o vestibular"; "poucos estudantes da escola pública conseguem entrar na Universidade Federal”. Ao perceber que "existe desigualdade tanto na escola pública quanto na privada, pois quem tem poder aquisitivo maior consegue vaga mais facilmente, muitas vezes tirando a vaga de quem precisa", alguns professores defendem que o "ensino superior público deveria ser só para quem vem de escolas públicas", além de se mostrarem sensíveis à discriminação entre os alunos das diferentes redes de ensino: "há muita comparação entre alunos de escolas públicas e particulares [pois] falta valorização para os alunos de escola pública".

\section{As duas faces do mérito escolar: interesse e esforço}

O mérito escolar figura como um quarto aspecto, sendo acionado a partir de facetas que se mesclam, de modo que os professores tendem a amenizar as desigualdades de oportunidades ou a vê-las como "desigualdades justas"13. Na opinião de muitos deles, o problema não está na falta de talentos ou de dons, mas na falta de

\footnotetext{
${ }^{13}$ Ao analisar as injustiças provenientes da experiência das desigualdades no trabalho, Dubet (2014) oferece uma conceitualização ampla e detalhada, recheada de exemplos, do que se entende por "desigualdades justas". Mas ele já havia feito referência a essa expressão quando desenvolveu sua reflexão sobre a "igualdade meritocrática das oportunidades", lembrando que a "dramaturgia esportiva é a metáfora mais fiel dessa maneira de fabricar desigualdades justas” (Dubet, 2008, p. 20).
} 
interesse tanto dos alunos quanto dos pais, pois "todos têm oportunidades iguais. Alguns não aproveitam. Alguns não querem, outros não podem”; “há muitas escolas, se não estudam é porque não querem"; “todos têm oportunidade, somente quem não quer estudar pensa diferente”; "depende do interesse pois a oportunidade é para cada um”; "hoje só não estuda quem não tem vontade"; "a oportunidade é oferecida mas pouco aproveitada”; “o que faz a diferença é o interesse”; "falta um pouco de boa vontade dos pais e jovens". Outra faceta do mérito escolar diz respeito ao esforço, que se coloca na contramão da oferta de oportunidades e acaba por “queimar as vítimas", como assinala Dubet (2008): “você tem que merecer”; “muitos não se esforçam, não estudam, querem de graça”; “depende do esforço”; “se correr atrás, até que não está tão ruim [...], mas escuta-se muita reclamação"; "basta ser esperto e aproveitar"; "para quem não fica esperando só pela escola, busca algo a mais, há maiores oportunidades”.

A questão formulada no início deste texto retorna com toda força no momento de sua finalização: É possível vislumbrarmos uma escola e uma universidade justas no Brasil? As duas figuras, notadamente os paradoxos da democratização da educação e a desigualdade distributiva das oportunidades, construídas a partir das representações de professores que viveram o magistério ao longo de suas carreiras profissionais, mostram que estamos diante de uma problemática orientada por pluralismos teóricos e por convicções axiológicas, produtores de leituras, interpretações e sentimentos não isentos de obscuridades, ou mesmo de contradições.

Ao relacionar sentimentos de injustiça desses professores com teorias da justiça, clássicas ou contemporâneas, chegamos ao menos a uma constatação central: a primeira experiência com a qual nos confrontamos não é a da justiça, mas a da injustiça. O fato de viver uma injustiça, como vítima, como espectador ou como ator, impele à busca de concepções interpretativas, que nem sempre se mostram claras e consequentes. Em outras palavras, toda aspiração a uma escola ou a uma universidade justas, assim como toda crítica prospectiva dirigida às políticas educacionais, foi motivada por experiências sentidas ou vivenciadas de injustiça.

Quatro constâncias se destacaram nos argumentos dos professores: 1) a igualdade perante a lei não garante a justiça, o que coloca em xeque os próprios fundamentos constitucionais: "justa seria se a escola alcançasse a todos os alunos com a mesma 
oportunidade de crescer e desenvolver suas capacidades"; "oportunidade de estudar existe, porém o nível do ensino continua deficiente"; 2) o direito existente favorece abertamente um grupo em relação a outro, e a justiça aparece como uma espécie de álibi ideológico, o que aponta para os obstáculos à justiça escolar em razão da coexistência de distintos sistemas no interior de um mesmo sistema (público, privado, federal, estadual, municipal): “o ensino superior público continua sendo para os que têm alto poder aquisitivo, apesar das cotas, ENEM, etc."; 3) a distribuição de vagas, pautada no princípio da igualdade, remete quase que exclusivamente à retribuição ou à reparação do mérito, o que revela o desequilíbrio entre o direito de todos e as políticas educacionais: "nem todos os inteligentes e esforçados são os recompensados"; "não deveria ter esta cota para negros. Se todos são iguais, por que isso?”; “não há necessidade de dar uniforme escolar para alunos. Isso é dever dos pais. Não acho isso conveniente. Esse dinheiro deveria ser empregado em material didático e tecnologias novas"; 4) os talentos são desigualmente repartidos, de modo que diferenças se transformam em injustiças, o que explicita a tensão/confusão entre as chamadas "loteria natural" e "loteria social”: "a escola prioriza os melhores, fortalecendo a desigualdade em todos os níveis".

Como se pode ver, ao consultarmos os professores sobre questões que envolvem diferentes princípios de justiça ${ }^{14}$, constatamos que eles reabilitam concepções teóricas altamente elaboradas para sustentar seus argumentos, como se estivessem familiarizados com o pensamento de Aristóteles, Rousseau, Rawls, Walzer, Moore, Dubet, ou tantos outros. Do mesmo modo, ao convidá-los a discorrer sobre o acesso e as condições de escolarização, os professores reconhecem os mecanismos de reprodução postos em prática pelo sistema de ensino; os professores percebem que a meritocracia escolar nada mais é do que a expressão ilusória de um sistema de privilégios.

Segundo Bourdieu (1994, p. 40), este sistema age como o demônio imaginado por Maxwell para comprovar a eficácia de uma das leis da termodinâmica. Este físico imagina um demônio que opera uma triagem entre as partículas mais ou menos quentes em movimento, enviando as mais rápidas para um recipiente cuja temperatura se eleva e as mais lentas para outro recipiente, no qual a temperatura baixa. Ou seja, os argumentos

\footnotetext{
${ }^{14}$ Ao convidar os professores a exprimirem seus pontos de vista sobre a justiça escolar, fomos mais uma vez surpreendidos com o interesse que essa questão despertou: $82 \%$ deles apresentaram seus pontos de vista ( $67 \%$ dos que atuaram de $1^{\mathrm{a}}$ a $4^{\mathrm{a}}$ série; $89 \%$ dentre os de níveis fundamental e médio).
} 
dos professores, ainda que possam parecer relativamente incoerentes, estão em forte sintonia com as abordagens críticas, relativas ao papel das políticas de democratização na (re)produção das injustiças escolares.

Torna-se, portanto, indiscutível que as concepções de justiça são elaboradas no complexo jogo das experiências profissionais e no confronto destas com experiências pessoais, amalgamando expectativas, sonhos, apostas, frustrações que atravessam uma vida toda. As representações sobre a democratização da educação explicitam, por conseguinte, contradições entre intenções e realizações, entre promessas e mudanças adotadas. Elas evidenciam lutas por poder e reconhecimento, expressam críticas que, apesar de contundentes, não conseguem instigar ações de grande impacto nas mudanças educacionais. Enfim, elas trazem à tona sentimentos de injustiça que passam a ser mais claramente compartilhados, sem, contudo, provocar um engajamento, subversivo (diria Moore), dos professores na igualdade de oportunidades educacionais e na construção de uma escola e universidade justas.

\section{Referências}

BOURDIEU, Pierre. Classificação, desclassificação, reclassificação. In: NOGUEIRA, Maria Alice; CATANI, Afrânio. Escritos de educação. Petrópolis: Vozes, 1998, p. 145-183.

BOURDIEU, Pierre. Raisons pratiques: sur la théorie de l'action. Paris: Seuil, 1994.

BOURDIEU, Pierre; PASSERON, Jean-Claude. Os herdeiros: os estudantes e a cultura. Florianópolis: Editora da UFSC, 2014.

BOURDIEU, Pierre; PASSERON, Jean-Claude . A reprodução: elementos para uma teoria do sistema de ensino. Rio de Janeiro: Francisco Alves, 1982, p. 151-226. 
CHARLOT, Bernard. Du rapport au savoir: elements pour une théorie. Paris: Anthropos, 1997.

DUBET, François. O que é uma escola justa? a escola das oportunidades. São Paulo: Cortez, 2008.

DUBET, François Injustiças: a experiência das desigualdades no trabalho. Florianópolis: EdUFSC, 2014.

LAHIRE, Bernard. Culture écrite et production des inégalités scolaires. In: RUANOBORBALAN, J.-C. Éduquer et former: les connaissances et les débats en éducation et en formation. Auxerre: Éditions Sciences Humaines, 1998, p. 483-90.

LANGOUËT, Gabriel. A escola francesa se democratiza, mas a inserção social torna-se cada vez mais difícil. Perspectiva: Revista do Centro de Ciências da Educação, Florianópolis: Editora da UFSC, v. 20, n. Especial, p. 85-106, jul./dez., 2002.

MOORE JÚNIOR, Barrington. Injustiça: as bases sociais da desobediência e da revolta. São Paulo: Brasiliense, 1987.

RAWLS, John. Uma teoria da justiça. $2^{\text {a }}$ ed. São Paulo: Martins Fontes, 2002.

ROHLING, Marcos; Valle. Princípios de justiça e justiça escolar: a educação multicultural e a equidade. Cadernos de Pesquisa, São Paulo: Fundação Carlos Chagas, v. 46, n. 160, p. 386-409, abr./jun., 2016.

VALLE, Ione Ribeiro. (In)Justiça escolar: estaria em xeque a concepção clássica de democratização da educação? Educação e Pesquisa: Revista da Faculdade de educação. São Paulo: USP, v. 39, n. 3, p. 659-671, jul./set., 2013.

VALLE, Ione Ribeiro. A escola não faz mais a diferença: as transformações da educação pública catarinense na ótica dos professores. Atos de Pesquisa em Educação, Blumenau: FURB, v. 9, p. 342-371, 2014a. Disponível:

<http://proxy.furb.br/ojs/index.php/atosdepesquisa/article/view/4445/2748>.

VALLE, Ione Ribeiro. A era da profissionalização. Formação e socialização profissional do corpo docente de $1^{\mathrm{a}}$ a $4^{\mathrm{a}}$ série. Florianópolis: Cidade Futura, 2003.

VALLE, Ione Ribeiro. Burocratização da educação: um estudo sobre o Conselho Estadual de Educação do Estado de Santa Catarina. Florianópolis: EdUFSC, 1996.

VALLE, lone Ribeiro. Sociologia da educação, currículo e saberes escolares. Florianópolis: EdUFSC, $2^{\text {a }}$ ed., 2014b.

VALLE, Ione Ribeiro. Justiça na escola: das desigualdades justas à igualdade sem adjetivos! In: Autor; SILVA, Vera Lúcia Gaspar da; DAROS, Maria das Dores (Orgs.).

Educação escolar e justiça social. Florianópolis: UFSC/NUP, 2010, p. 19-48. 
VALLE, lone Ribeiro. O lugar da educação nos projetos de modernidade: escola e diferenciação social. In: VALLE, Ione Ribeiro; HAMDAN, Juliana Cesário; DAROS, Maria das Dores (Orgs.). Moderno, Modernidade, Modernização: a educação nos projetos de Brasil - séculos XIX e XX. Belo Horizonte: Mazza Edições, v. 2, 2014c, p. 17-35.

WALZER, Michael. Esferas da justiça: uma defesa do pluralismo e da igualdade. São Paulo: Martins Fontes, 2003.

Recebido em: 11/04/2018 Aprovado em: 09/06/2018

Universidade do Estado de Santa Catarina - UDESC Programa de Pós-Graduação em Educação - PPGE Revista Linhas Volume 19 - Número 41 - Ano 2018 revistalinhas@gmail.com 